\section{Correlation between Trunk-Pelvis Inter- Segmental Coordination Parameters during Walking and Disability Level in Chronic Low Back Pain Patients}

\author{
Ebrahimi S. ${ }^{1,2}$, Kamali F.,2*, Razeghi M. ${ }^{1,2}$, Haghpanah S. A. ${ }^{3}$
}

\begin{abstract}
Background: Chronic low back pain (CLBP) disability has been particularly frustrating because its treatment has been a great therapeutic challenge. Disability has been suggested to depend on different factors that should be found and considered in the medical management. The inter-segmental coordination is often impaired in CLBP subjects; however, to the best of our knowledge, there is no evidence about the relationship between the existence of coordination problems and disability in CLBP patients.
\end{abstract}

Objective: To evaluate the correlation between sagittal plane trunk-pelvis intersegmental coordination parameters during walking and disability level in CLBP patients.

Methods: Kinematic data were collected from 16 non-specific CLBP (18-40 years) volunteers during walking. Sagittal plane time-normalized segmental angles and velocities were used to calculate continuous relative phase for each data point. Coordination parameters, mean absolute relative phase (MARP) and deviation phase (DP) were derived to quantify the trunk-pelvis coordination pattern and variability during gait cycles, respectively. The disability level was quantified through Oswestry Disability Index (ODI) questionnaire. Pearson correlation coefficient was used to find the probable correlation between coordination parameters and disability level.

Results: The analysis demonstrated a significant correlation between sagittal plane MARP or DP and disability level (\%ODI) in CLBP subjects during walking ( $\mathrm{r}=$ $-0.806 \mathrm{P}<0.001$ and $\mathrm{r}=-0.856, \mathrm{P}<0.001$, respectively).

Conclusion: This study demonstrated that the lower the MARP (more in-phase pattern) and DP (less variable pattern) in the CLBP subjects, the more disability existing in such patients. The results suggest that clinicians should look beyond pain management when prescribing rehabilitation for CLBP and consider interventions that target segmental coordination improvement to manage CLBP induced disability.

\section{Keywords}

Chronic Low Back Pain, Continuous Relative Phase, Gait, Biomechanics, Disability

\section{Introduction}<smiles>C1CCCCCC1</smiles>
hronic low back pain (CLBP) is the most prevalent musculoskeletal disorder known as a common reason for functional disability and work absenteeism worldwide [1]. It affects $70 \%$ to $85 \%$ of people at some moment during their lifetime [2]; however, up to $85 \%$ of patients with LBP are classified as LBP with unknown origin or non-
${ }^{1}$ Department of Physical Therapy, School of Rehabilitation Sciences, Shiraz University of Medical Sciences, Shiraz, Iran ${ }^{2}$ Rehabilitation Sciences Research Center, Shiraz University of Medical Sciences, Shiraz, Iran ${ }^{3}$ School of Mechanical Engineering, Sharif University of Technology, Tehran, Iran

*Corresponding author: F. Kamali

School of Rehabilitation Sciences, Shiraz University of Medical Sciences, Abiverdi 1 Ave., Chamran Blvd, Shiraz, Fars, Iran E-mail: fahimehkamali@ hotmail.com

Received: 5 July 2016 Accepted: 12 August 2017 
specific LBP [3].

Disability, which affects the quality of life and usually leads to work loss, is defined as impairment induced restricted function [4]. CLBP induced disability continues to afflict patients and to stress the health and industrial economies. However, it has been particularly frustrating, and the treatment of disability has been a therapeutic dilemma [5]. CLBP related disability, a multifactorial condition [6], has been suggested to depend on different factors than solely the severity of pain [7]; therefore, these factors should be found and considered in the medical management. It has been stated that motor control deficiencies during walking may exert excessive and abnormal stresses on the lumbar spine, which may contribute to the creation or existence of CLBP and disability [8].

The coordination pattern and coordination variability parameters have been assumed as substantial features of human motion that provide important data on motor control changes in patients [9]. Lamoth et al. stated that coordination problems are the base of many other locomotion problems in patients with CLBP [10]. On the other hand, several studies have shown abnormal coordination patterns and coordination variability in individuals with CLBP during dynamic motions such as gait $[9,11]$. These studies demonstrated decreased trunk-pelvis inter-segmental coordination pattern and coordination variability in CLBP subjects during walking, the main function in human life, which could exhibit "guarded gait" in CLBP individuals and affect the subjects' normal locomotion $[9,11]$. Nonetheless, there is inadequate correlation between these investigative findings and clinical symptoms.

Recent advances in non-linear dynamic field present higher-order variables such as inter-segmental coordination and variability in contrast to lower-order variables (conventional gait analysis) such as kinematic/kinetic assessments to better capture the underlying coordination dynamics in motor tasks [12, 13]. These measures are very helpful for understanding how the neuromuscular and musculoskeletal systems achieve a precise and smooth functional activity by organizing the redundant joints degrees of freedom [14]. Inter-segmental coordination analysis describes the segments spatio-temporal organization in relation to each other to identify movement patterns [15]. It is the ability to maintain accurate relationships between segments to make a functional movement in an organized time/ sequential manner [16].

Based on the dynamic system theory approach, one of the techniques applied to quantify the coordination pattern, is continuous relative phase (CRP) [17]. CRP can correlate with both angular position and velocity information of two segments or joints continuously during the movement [18]. Moreover, CRP variability can quantify the variation in the neuromuscular system organization [19]. It has been stated that these parameters are more suitable for determining related motor control mechanisms in movement [20].

Since multi-segmental coordination impairment often accompanies pathology that can affect the life quality, improvement of intersegment coordination has been an important goal in rehabilitation $[11,18]$. However, to the best of our knowledge, there is no evidence about the relationship between the existence of coordination problems and disability in CLBP patients.

Therefore, the aim of this study was to find if there is any correlation between sagittal plane trunk-pelvis inter-segmental coordination parameters during free-speed walking and disability levels in CLBP patients. We hypothesize that there is a relationship between trunk-pelvis coordination parameters and disability level in subjects with CLBP.

The results of this study might be helpful to find one of the probable factors contributing to disability in CLBP patients and considering 
that in the treatment protocols to have more efficient and appropriate rehabilitation for disability treatment.

\section{Material and Methods}

\section{Participants}

Sixteen right-leg dominant subjects (8 males, 8 females, age: $30.50 \pm 5.72$ yrs, weight: $66.61 \pm 10.68 \mathrm{~kg}$, height: $168 \pm 8.87 \mathrm{~cm})$ with non-specific CLBP participated in this study.

The patients were selected from subjects referred by orthopedists with non-specific CLBP diagnosis to physical therapy clinics of Shiraz University of Medical Sciences. An expert physical therapist carefully assessed the subjects for inclusion and exclusion criteria. The patients were included in this study if they were 18-40 years old and had a history of at least 3 months LBP with unknown origin [21].

The subjects were excluded if they had any deformity in the spines or lower limbs, tumors or infection, neurologic/orthopedic or sensory disorders, lower limbs, trunk or pelvis history of fractures or surgical interventions, rheumatoid disease, spondylolisthesis, radicular pain to lower limbs, balance disorders, had received physical therapy in the past three months and had taken anti-inflammatory/analgesic medicine in the past 48 hours.

The current research was conducted at the Rehabilitation Sciences Research Center, Shiraz University of Medical Sciences, Shiraz, Iran. A detailed explanation of the procedure is provided and all the participants signed an informed consent form approved by the university ethics committee.

\section{Data Collection}

CLBP disability level was measured and quantified using a reliable and valid Persian version of Oswestry Disability Index (ODI) questionnaire [22]. The ODI questionnaire, which is one of the most frequently used tools for measuring chronic disability [23], is composed of 10 six-point scale questions (each question has a scale from 0 to 5) which measures LBP disability in different activities of daily living. CLBP patients were asked to mark the best answer according to their state in each section. Then, the scores were measured; the higher the score, the greater the disability. The final ODI score ranges from $0 \%$ to $100 \%$, with $0 \%$ indicating no disability and $100 \%$ reflecting maximum disability [24].

Kinematic data were collected using an eight-camera motion analysis system (Proreflex, Qualisys Track Manager ${ }^{\circledR}$ Ltd., Sweden) at a sampling rate of $100 \mathrm{~Hz}$. Infrared reflective markers with $19 \mathrm{~mm}$ diameter were attached to the specific landmarks based on the Visual 3D marker set-up to build a 6-degree of freedom model. The landmarks were as follows: acromions, C7 and T10 spinous processes, right and left upper and lower back, sternum (xyphoid process), highest point of iliac crests, anterior and posterior iliac spines and center of greater trochanters (Figure 1). To be able to detect the gait cycles, reflective markers were placed on the center of calcanei and the second metatarsal heads.

After several practice trials, the subjects were asked to walk barefoot along an 8-m walkway at a comfortable preferred speed, and data were collected from 5-6 walking trials (at least 20 complete gait cycles). To build the model, a standing static trial was captured prior to recording dynamic trials. The subjects were instructed to retain their visual contact with a fixed point located at the end of the walkway at their eye level to enhance a natural gait pattern,

Raw data were filtered with a low-pass, fourth order Butterworth filter with a cut-off frequency of $6 \mathrm{~Hz}$ using Visual3D motion analysis software (C-Motion $\AA$, Rockville, MD, USA). Trunk and pelvis were modelled as rigid segments and their segmental angels in the sagittal plane were calculated through Visual3D software. 

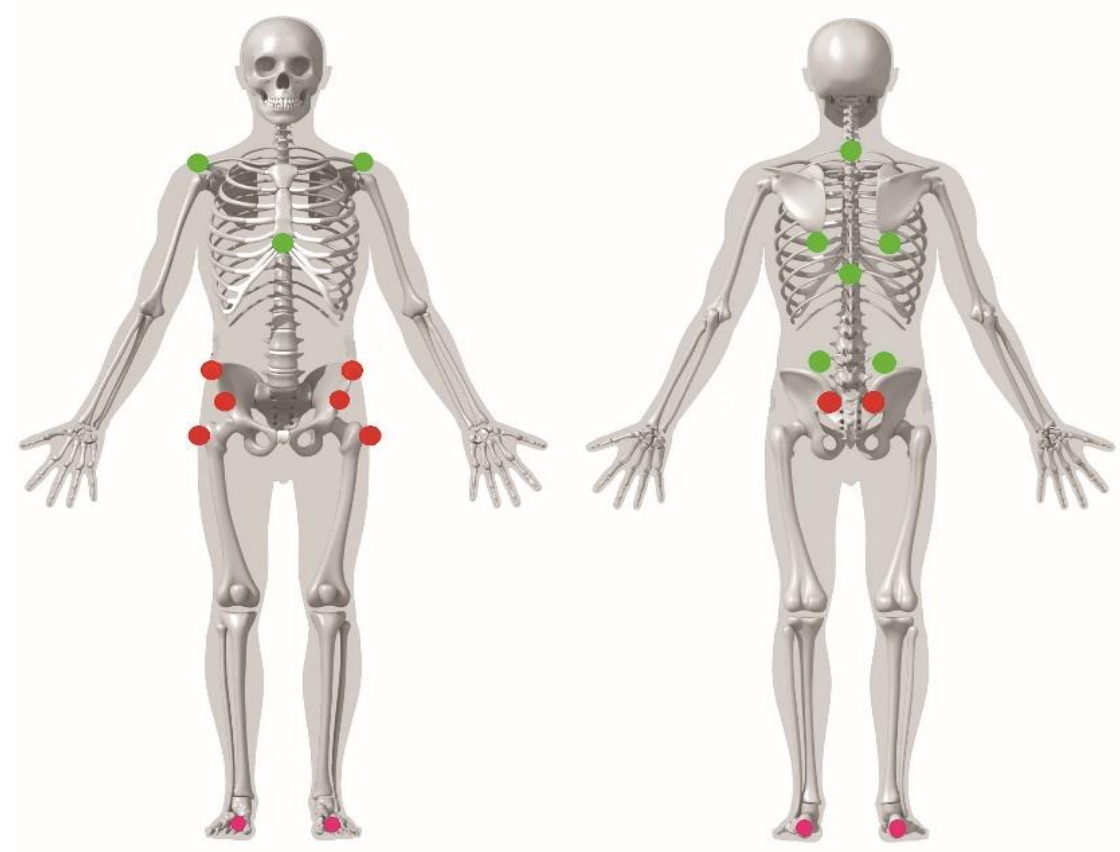

Figure 1: Marker set-up used for model building

\section{Inter-segmental Coordination Anal-} ysis

The events of heel strike and toe-off were detected by high pass algorithm (HPA) method [25]. In addition, the detected events were confirmed visually by the researcher for the plausible inaccurate detected events due to the lost marker data.

Inter-segmental coordination was assessed by the CRP technique. A custom written Matlab $\AA$ program, version 7.12.0 (Mathworks Inc., Natick, MA, USA) was utilized to calculate the coordination values.

The time series of trunk and pelvis angles were obtained and interpolated to $100 \%$ of complete gait cycle using cubic spline function. Empirical mode decomposition algorithm was applied to affirm the assumption of applying phase portrait and dynamic system, which required sinusoid signals. Segmental angles were first decomposed into empirical modes and then the time series reconstructed with all of them except the lowest frequencies [26].
Segmental angular velocities in the sagittal plane were extracted from the calculated angles using a first central difference method [11].

For CRP calculation, phase portraits of trunk and pelvis were generated by plotting each segments normalized angular position $\left(\theta_{i . n o r m}\right)$ against its normalized angular velocity $\left(\omega_{\text {i.norm }}\right)$ [26].

Angular positions were normalized to a range between 1 and -1 with zero located on its midpoint and angular velocities were normalized to the maximum absolute velocity during the movement; zero was assumed as zero velocity [18]. The normalizations in each gait cycle were done through following equations:

Horizontal axis: $\theta_{i \text {.norm }}=2 \times\left[\theta_{i}-\min \left(\theta_{i}\right)\right] /$ $\left[\max \left(\theta_{i}\right)-\min \left(\theta_{i}\right)\right]-1, \mathrm{i}=1 \ldots 100$

$\theta_{i}=$ angular position for each of the 100 interpolated data points during a complete gait cycle.

Vertical axis: $\omega_{\text {i.norm }}=\omega_{i} / \max \left(\left|\omega_{i}\right|\right)$, $\mathrm{i}=1 \ldots 100$

$\omega_{i}=$ angular velocity for each of 100 interpo- 
lated data points during a complete gait cycle.

Then, the phase angles $(\varphi)$ were calculated for each data point through the entire gait cycle:

$\varphi_{i}=\tan ^{-1}\left(\omega_{\text {i.norm }} / \theta_{\text {i.norm }}\right)$ (Figure 2).

Next, the CRP curve was derived for trunkpelvis coupling from the absolute value of the difference between phase angles of trunk and pelvis at every point during the gait cycle: $C R P_{\text {trunk-pelvis }}=\left|\varphi_{\text {trunk }}-\varphi_{\text {pelvis }}\right|$

CRP values close to $0^{\circ}$ demonstrate more "in-phase" motion meaning that the movements of the two segments are in a similar fashion, and CRP values close to $180^{\circ}$ depicting more "out of-phase" motion, denoting that the movements of the two segments are in opposite fashion [27]. It should be noted that to avoid discontinuities in CRP, adjustments were made by subtracting the values greater than $180^{\circ}$ from $360^{\circ}$ [11].

In the next step, the trunk-pelvis CRP curves were averaged across the 20 gait cycles and the mean ensemble average curves were generated for all participants. To quantify CRP curves, two extra values of mean absolute relative phase (MARP) and deviation phase (DP) were calculated using ensemble curves.

MARP was calculated by averaging the absolute values of all the ensemble curve date points over the gait cycle using the following equation: $M A R P=\sum_{i=1}^{100}|C R P|_{i} / 100$

Lower MARP values demonstrate a more "in-phase" oscillation between the two segments and higher MARP values illustrate a more "out of phase" relationship between the segments [28].

Deviation phase (DP) was calculated by averaging the standard deviations of the ensemble CRP curve over the gait cycle to quantify the coordination variability: $D P=\sum_{i=1}^{100} S D_{i} / 100$

Lower DP values indicate a less variable relationship between the two segments or a more stable coordination pattern within trials [28].

\section{Statistical Analysis}

The processed data were statistically analyzed using IBM ${ }^{\circledR}$ SPSS, version 21.0 (IBM Corp, Armonk, NY, USA). Pearson's correlation coefficient (r) was used to find the probable relationship between coordination pa-

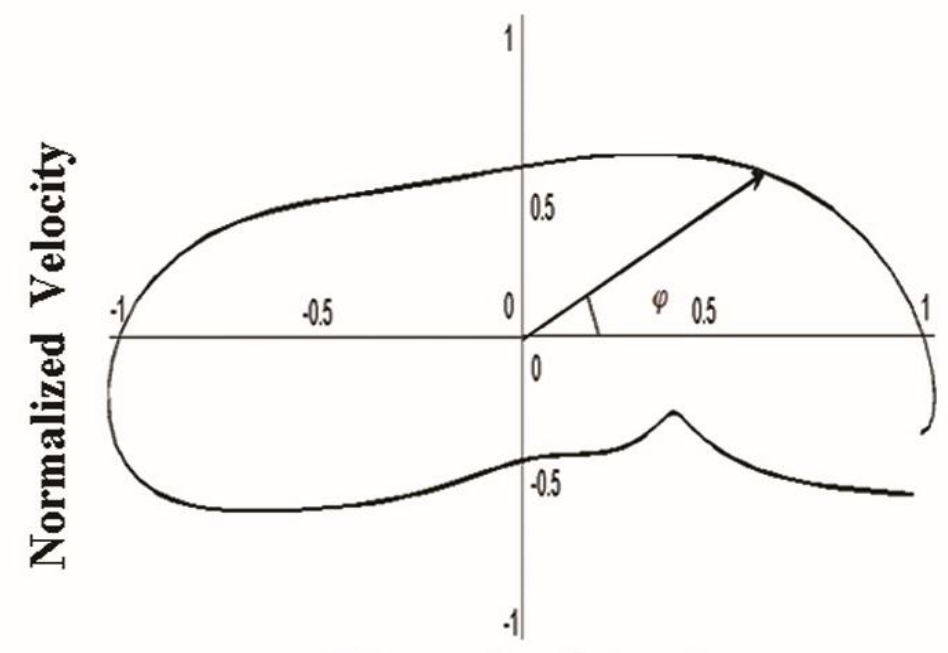

Normalized Angle

Figure 2: An exemplar phase angle $(\varphi)$ on a phase portrait 
rameters (MARP, DP) and disability level in CLBP subjects. The significance level was set at 0.05 for statistical analyses.

\section{Results}

The statistical analysis demonstrated a significant negative correlation between sagittal plane MARP or DP and disability level (\%ODI) in CLBP subjects during walking $(\mathrm{r}=-0.806, \mathrm{P}<0.001$ and $\mathrm{r}=-0.856, \mathrm{P}<0.001$ respectively) (Figures 3 and 4).

\section{Discussion}

In the current study, we investigated the relationship between sagittal plane trunk-pelvis coordination parameters (MARP, DP) and disability level (\%ODI) in CLBP subjects. We hypothesized that there was a correlation between mentioned parameters and CLBP disability; our results support this hypothesis.

The results of the present study demonstrated that the lower the MARP (more in-phase pattern) and DP (less variable pattern) in the CLBP subjects, the more disability existing in these patients. Low MARP and DP values of trunk-pelvis coupling augment the concept of "protective guarding behavior" in patients with LBP [11].

These results are consistent with those of previous literature which demonstrated that other factors rather than solely pain can affect the CLBP patients' disability level [6, 7, 29, 30].

Previous studies have demonstrated that CLBP is a multifactorial condition with several dysfunctions [6] that seems to induce different associated problems such as disability.

Gordon Waddell et al. (1993) showed that disability in subjects with CLBP during activities of daily living was related to the pain severity and physical impairment; however, the relationship was weak. They stated that the pain severity accounted only for $10 \%$ of the disability and physical impairment [7]. Moreover, Kovacs F.M et al. studied the correlation between the pain severity, disability level and the quality of life in 195 patients. They stated that only minimal changes in patients' disability levels and quality of life is detectable after clinically significant improvements in pain

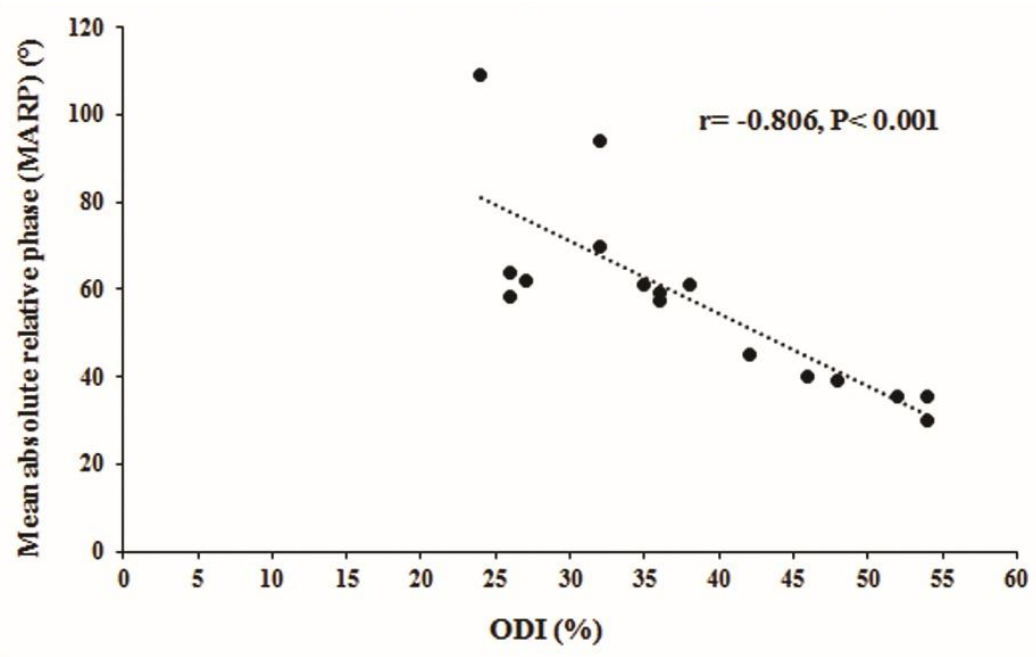

Figure 3: The correlation between sagittal plane MARP and disability level (\%ODI) in CLBP subjects during walking 


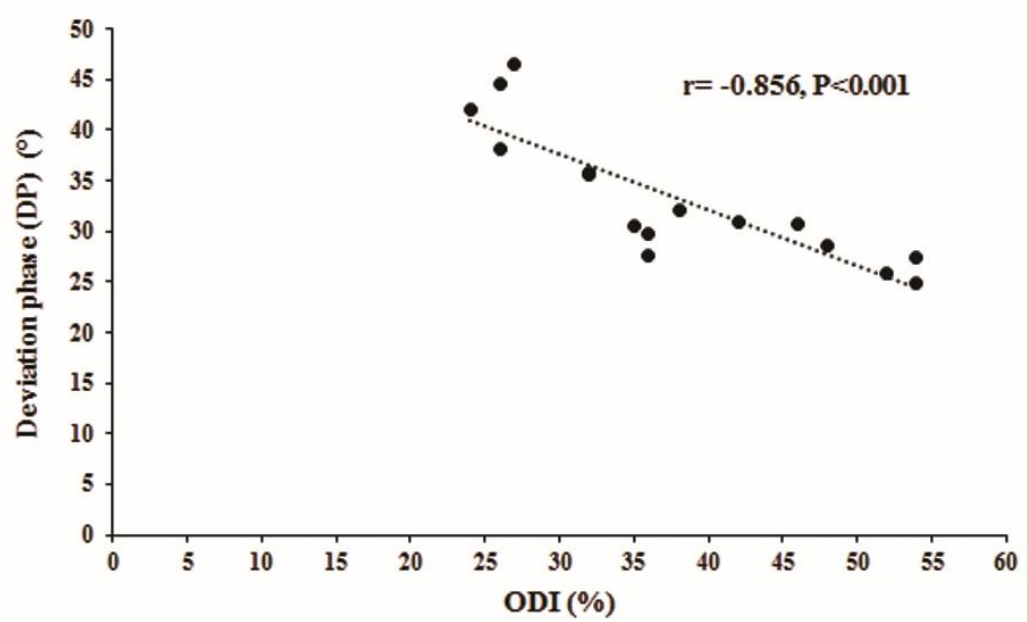

Figure 4: The correlation between sagittal plane DP and disability level (\%ODI) in CLBP subjects during walking

[29]. Therefore, it has been suggested that CLBP related disability must depend on other factors than only the severity of pain or physical impairment [7], which should be found and considered the medical management.

On the other hand, the findings of numerous studies on CLBP subjects are suggestive of abnormal trunk-pelvis inter-segmental coordination during different tasks $[10,11,19]$. It has been stated that alterations in the trunkpelvis coordination and coordination variability in these patients might occur due to various problems associated with CLBP. Pain induced abnormal neuromuscular coordination control [31], changed trunk muscles' activity control (neuromuscular control) [32, 33] and impaired proprioception [34] are problems that might result in abnormal inter-segmental coordination in CLBP patients. Cosequently, it may be responsible for the development of disability associated with CLBP.

As it has been stated later the lumbopelvis region has a substantial role in human body. The pelvis segment, in terms of biomechanics, is a very important segment located in the center of body and therefore connects the up- per and lower limbs segments [35]. It has been stated that the normal stability of pelvis and trunk is necessary for all movements done by lower and upper extremities [36]. Accordingly, the upper and lower extremities motions could be affected by any alterations in the lumbopelvis region coordination control/stability. So, considering the important role of lumbopelvis region in the human body, the obtained results about the correlation between trunk-pelvis coordination dysfunctions (reduced MARP and DP) and disability level were not surprising and seem reasonable.

These results, combined with disability level, indicate that clinicians should look beyond resolution of pain when prescribing rehabilitation for CLBP to manage the patients' disability in daily life. It can be stated that the relationship between three-dimensional nature of our reported coordination in sagittal plane and disability level, might indicate that clinicians should consider interventions that target segmental position and velocity components in the sagittal plane of motion to manage the CLBP induced disability and associated problems. 
The trunk-pelvis coordination assessments were limited to the sagittal plane in the current study, due to the fact that sagittal is the primary motion plane during walking. It can be suggested that future studies address other motion planes to see if there is probable relationship between coordination parameters and disability levels, therefore, helping the therapist and clinicians to have a more effective treatment protocol. Moreover, future studies might investigate whether exercise interventions for trunk-pelvis coordination recovery can improve the disability seen in patients with CLBP.

\section{Acknowledgment}

The authors would like to express their thanks to all patients participated in the study. The present article was extracted from a $\mathrm{PhD}$ thesis written by Samaneh Ebrahimi and was financially supported by Shiraz University of Medical Sciences Grant No. 6986. The authors would like to acknowledge scientific and financial support from Shiraz University of Medical Sciences, the Deputy for Research Affairs and the School of Rehabilitation Sciences.

\section{Conflict of Interest}

The authors declare no conflict of interests.

\section{References}

1. Lawford BJ, Walters J, Ferrar K. Does walking improve disability status, function, or quality of life in adults with chronic low back pain? A systematic review. Clin Rehabil. 2016;30:523-36. doi. org/10.1177/0269215515590487. PubMed PMID: 26088673.

2. Andersson GB. Epidemiological features of chronic low-back pain. Lancet. 1999;354:581-5. doi. org/10.1016/S0140-6736(99)01312-4. PubMed PMID: 10470716.

3. White AA, 3rd, Gordon SL. Synopsis: workshop on idiopathic low-back pain. Spine (Phila Pa 1976). 1982;7:141-9. doi.org/10.1097/00007632198203000-00009. PubMed PMID: 6211779.

4. Waddell G, Main CJ. Assessment of severity in low- back disorders. Spine (Phila Pa 1976). 1984;9:2048. doi.org/10.1097/00007632-198403000-00012. PubMed PMID: 6233713.

5. Hazard RG, Haugh LD, Green PA, Jones PL. Chronic low back pain: The relationship between patient satisfaction and pain, impairment, and disability outcomes. Spine (Phila Pa 1976). 1994;19:8817. doi.org/10.1097/00007632-199404150-00003. PubMed PMID: 8009344.

6. Steele J, Bruce-Low S, Smith D, Jessop D, Osborne N. Lumbar kinematic variability during gait in chronic low back pain and associations with pain, disability and isolated lumbar extension strength. Clin Biomech (Bristol, Avon). 2014;29:1131-8. doi. org/10.1016/j.clinbiomech.2014.09.013. PubMed PMID: 25451860.

7. Waddell G, Newton M, Henderson I, Somerville D, Main CJ. A Fear-Avoidance Beliefs Questionnaire $(F A B Q)$ and the role of fear-avoidance beliefs in chronic low back pain and disability. Pain. 1993;52:157-68. doi.org/10.1016/03043959(93)90127-B. PubMed PMID: 8455963.

8. Vogt L, Pfeifer K, Portscher, Banzer W. Influences of nonspecific low back pain on three-dimensional lumbar spine kinematics in locomotion. Spine (Phila Pa 1976). 2001;26:1910-9. doi.org/10.1097/00007632-200109010-00019. PubMed PMID: 11568705.

9. Lamoth CJ, Meijer OG, Daffertshofer A, Wuisman $\mathrm{PI}$, Beek PJ. Effects of chronic low back pain on trunk coordination and back muscle activity during walking: changes in motor control. Eur Spine J. 2006;15:23-40. doi.org/10.1007/s00586-0040825-y. PubMed PMID: 15864670. PubMed PMCID: 3454567.

10. Lamoth CJ, Daffertshofer A, Meijer OG, Beek PJ. How do persons with chronic low back pain speed up and slow down? Trunk-pelvis coordination and lumbar erector spinae activity during gait. Gait Posture. 2006;23:230-9. doi.org/10.1016/j.gaitpost.2005.02.006. PubMed PMID: 16399520.

11. Seay JF, Van Emmerik RE, Hamill J. Low back pain status affects pelvis-trunk coordination and variability during walking and running. Clin Biomech (Bristol, Avon). 2011;26:572-8. doi.org/10.1016/j. clinbiomech.2010.11.012. PubMed PMID: 21536356.

12. Yen HC, Chen HL, Liu MW, Liu HC, Lu TW. Age effects on the inter-joint coordination during obstacle-crossing. J Biomech. 2009;42:2501-6. doi. org/10.1016/j.jbiomech.2009.07.015. PubMed PMID: 19665128. 
13. Hamill J, McDermott WJ, Haddad JM. Issues in quantifying variability from a dynamical systems perspective. Journal of Applied Biomechanics. 2000;16(4). doi.org/10.1123/jab.16.4.407.

14. Bernstein NA. The co-ordination and regulation of movements. Pergamon Press: Oxford; 1967.

15. Hutin E, Pradon D, Barbier F, Gracies JM, Bussel $B$, Roche N. Lower limb coordination patterns in hemiparetic gait: factors of knee flexion impairment. Clin Biomech (Bristol, Avon). 2011;26:30411. doi.org/10.1016/j.clinbiomech.2010.10.007. PubMed PMID: 21074912.

16. Ghanavati T, Salavati M, Karimi N, Negahban $H$, Ebrahimi Takamjani I, Mehravar M, et al. Intra-limb coordination while walking is affected by cognitive load and walking speed. J Biomech. 2014;47:23005. doi.org/10.1016/j.jbiomech.2014.04.038. PubMed PMID: 24861632.

17. Kelso JS. Dynamic patterns: The self-organization of brain and behavior. London: MIT press; 1997.

18. Hamill J, van Emmerik RE, Heiderscheit BC, Li L. A dynamical systems approach to lower extremity running injuries. Clin Biomech (Bristol, Avon). 1999;14:297-308. doi.org/10.1016/S02680033(98)90092-4. PubMed PMID: 10521606.

19. Mokhtarinia HR, Sanjari MA, Chehrehrazi M, Kahrizi S, Parnianpour M. Trunk coordination in healthy and chronic nonspecific low back pain subjects during repetitive flexion-extension tasks: Effects of movement asymmetry, velocity and load. Hum Mov Sci. 2016;45:182-92. doi.org/10.1016/j. humov.2015.11.007. PubMed PMID: 26684726.

20. Worster K, Valvano J, Carollo JJ. Sagittal plane coordination dynamics of typically developing gait. Clin Biomech (Bristol, Avon). 2015;30:366-72. doi. org/10.1016/j.clinbiomech.2015.02.013. PubMed PMID: 25753695.

21. Airaksinen 0, Brox JI, Cedraschi C, Hildebrandt J, Klaber-Moffett J, Kovacs F, et al. Chapter 4. European guidelines for the management of chronic nonspecific low back pain. Eur Spine J. 2006;15:S192-300. doi.org/10.1007/s00586-0061072-1. PubMed PMID: 16550448. PubMed PMCID: 3454542.

22. Mousavi SJ, Parnianpour M, Mehdian H, Montazeri A, Mobini B. The Oswestry Disability Index, the Roland-Morris Disability Questionnaire, and the Quebec Back Pain Disability Scale: translation and validation studies of the Iranian versions. Spine (Phila Pa 1976). 2006;31:E454-9. doi.org/10.1097/01.brs.0000222141.61424.f7. PubMed PMID: 16778675.
23. Ciccone DS, Just N, Bandilla EB. Non-organic symptom reporting in patients with chronic non-malignant pain. Pain. 1996;68:329-41. doi. org/10.1016/S0304-3959(96)03216-2. PubMed PMID: 9121822.

24. Fairbank JC, Couper J, Davies JB, O'Brien JP. The Oswestry low back pain disability questionnaire. Physiotherapy. 1980;66:271-3. PubMed PMID: 6450426.

25. Desailly E, Daniel Y, Sardain P, Lacouture P. Foot contact event detection using kinematic data in cerebral palsy children and normal adults gait. Gait Posture. 2009;29:76-80. doi.org/10.1016/j.gaitpost.2008.06.009. PubMed PMID: 18676147.

26. Chiu SL, Chou LS. Effect of walking speed on inter-joint coordination differs between young and elderly adults. J Biomech. 2012;45:275-80. doi. org/10.1016/j.jbiomech.2011.10.028. PubMed PMID: 22078272.

27. Meyns P, Van Gestel L, Bruijn SM, Desloovere K, Swinnen SP, Duysens J. Is interlimb coordination during walking preserved in children with cerebral palsy? Res Dev Disabil. 2012;33:1418-28. doi. org/10.1016/j.ridd.2012.03.020. PubMed PMID: 22522200.

28. Stergiou N, Jensen JL, Bates BT, Scholten SD, Tzetzis G. A dynamical systems investigation of lower extremity coordination during running over obstacles. Clin Biomech (Bristol, Avon). 2001;16:213-21. doi.org/10.1016/S02680033(00)00090-5. PubMed PMID: 11240056.

29. Kovacs FM, Abraira V, Zamora J, Teresa Gil del Real M, Llobera J, Fernandez C, et al. Correlation between pain, disability, and quality of life in patients with common low back pain. Spine (Phila $P a$ 1976). 2004;29:206-10. doi.org/10.1097/01. BRS.0000107235.47465.08. PubMed PMID: 14722416.

30. Vlaeyen JW, Crombez G. Fear of movement/(re) injury, avoidance and pain disability in chronic low back pain patients. Man Ther. 1999;4:187-95. doi.org/10.1054/math.1999.0199. PubMed PMID: 10593107.

31. Radin EL, Yang KH, Riegger C, Kish VL, O’Connor JJ. Relationship between lower limb dynamics and knee joint pain. J Orthop Res. 1991;9:398-405. doi.org/10.1002/jor.1100090312. PubMed PMID: 2010844.

32. Arendt-Nielsen L, Graven-Nielsen T, Svarrer $H$, Svensson $P$. The influence of low back pain on muscle activity and coordination during gait: a clinical and experimental study. Pain. 1996;64:231-40. 
doi.org/10.1016/0304-3959(95)00115-8. PubMed PMID: 8740599.

33. Newcomer KL, Jacobson TD, Gabriel DA, Larson $\mathrm{DR}$, Brey RH, An KN. Muscle activation patterns in subjects with and without low back pain. Arch Phys Med Rehabil. 2002;83:816-21. doi.org/10.1053/ apmr.2002.32826. PubMed PMID: 12048661.

34. Brumagne $S$, Cordo P, Lysens R, Verschueren S, Swinnen $S$. The role of paraspinal muscle spindles in lumbosacral position sense in individuals with and without low back pain. Spine (Phila Pa 1976).
2000;25:989-94. doi.org/10.1097/00007632200004150-00015. PubMed PMID: 10767813.

35. Khamis S, Yizhar Z. Effect of feet hyperpronation on pelvic alignment in a standing position. Gait Posture. 2007;25:127-34. doi.org/10.1016/j.gaitpost.2006.02.005. PubMed PMID: 16621569.

36. Bouisset S. Relationship between postural support and intentional movement: biomechanical approach. Arch Int Physiol Biochim Biophys. 1991;99:A7792. doi.org/10.3109/13813459109145919. PubMed PMID: 1720694. 